\title{
VARIAÇÃO ESTACIONAL DAS CARACTERÍSTICAS SENSORIAIS DA TANGERINA-'PONCÃ' EM BRASÍLIA, DF ${ }^{1}$
}

\author{
JOSIANA ZANOTELLI DOS SANTOS² \& ANTÔNIO TUBELIS ${ }^{3}$
}

\begin{abstract}
RESUMO - Estudou-se a variação temporal das características sensoriais de tangerina-'Poncã' produzida sobre porta-enxertos de limoeiros- 'Cravo' e 'Rugoso da África', tangerineira- 'Oneco', citrangeleiro- 'Morton' e citromeleiro- 'Swingle 4475', nas condições edafoclimáticas de Brasília, no Distrito Federal, na safra de 1999/2000. Analisaram-se as características, aspecto e sucosidade do gomo , gosto, doçura, acidez e relação doçura/acidez da fruta. Avaliou-se também o conjunto de características sensoriais pelos critérios Nota. Verificou-se que as características e critérios avaliados tiveram um comportamento diferenciado durante o período de amostragem. Verificou-se que os porta-enxertos exerceram influência diferenciada nas características sensoriais da tangerina-'Poncã'. A classificação dos frutos pelo critério Nota conduziu aos seguintes resultados: Muito Boa nos períodos de 16 de maio a 27 de junho para o portaenxerto citrangeleiro- 'Morton', de 16 de maio a 20 de junho para a tangerineira- 'Oneco', de 23 de maio a 04 de julho para o limoeiro'Rugoso da África', de 16 de maio a 06 de junho para o citromeleiro- 'Swingle 4475' e em 27 de junho para o limoeiro- 'Cravo'; Boa nos períodos de 20 de junho a 27 de junho para o porta-enxerto tangerineira.
\end{abstract}

Termos de indexação: 1. Características sensoriais. 2. Tangerina. 3. Poncã. 4. Porta-enxerto

\section{SEASONAL VARIATION OF THE SENSORIAL CHARACTERISTICS OF 'PONKAN' TANGERINE FRUITS IN BRASÍLIA, FEDERAL DISTRICT, BRAZIL}

\begin{abstract}
The seasonal variation of the sensorial characteristics of 'Ponkan' tangerine fruits grown on 'Rangpur' and 'Rough of Africa' lemons, 'Oneco' tangerine, 'Morton' citrange and 'Swingle 4475' citrumelo, was studied during the crop of 1999/2000. It was analyzed the sensorial characteristics of pulpy segment of the fruit: the aspect, taste, sweetness, acidity, sweetness/acidity ratio and succulence. It was also evaluated the whole of sensorial characteristics by the criterion Note. It was verified that the rootstocks affected differently the sensorial characteristics of the 'Ponkan' tangerine. The rootstock induced differences in the sensorial characteristics of the fruit, allowing defining its classification by the sensorial profile. The classification of the fruits by the Note criterion led to the following results: very good during the periods from May 16 until June 27 for the 'Morton' citrange rootstock, from May 16 until June 20, for 'Oneco' tangerine; from May 23 until July 4, for 'Rough of Africa' lemon; from May 16 until June 6 for 'Swingle 4475' citrumelo and at June 27 for 'Rangpur' lime; and good during the periods from June 20 until June 27 for the 'Oneco' tangerine rootstock; from May 23 until June 13 for 'Rough of Africa' lemon; from June 6 until June 27 for 'Swingle 4475' citrumelo and from June 13 until June 20 for 'Rangpur' lime.
\end{abstract}

Index terms: 1. Sensorial characteristics. 2. Tangerine. 3. Ponkan. 4. Rootstock

\section{INTRODUÇÃO}

A tangerineira-'Poncã' é originária da Índia e, devido as suas boas qualidades, difundiu-se rapidamente através do oriente. Ela foi introduzida na Europa por volta de 1805 e nos Estados Unidos em 1892-93 (Hodgson, 1967). Da Flórida, ela foi introduzida no Estado de São Paulo, em 1947/48, pela Estação Experimental de Limeira e pela Dierberger. O Brasil é o quarto maior produtor mundial de tangerinas (CCSM, 2001), sendo que mais de $60 \%$ das tangerinas produzidas se refere à 'Poncã'. As características químicas e físicas da tangerina-'Poncã' produzidas no Brasil são razoavelmente conhecidas. Contudo, estas características são usadas para definir a qualidade dos frutos para a industrialização. Como a quase totalidade da produção de tangerineira-'Poncã' é destinada para o consumo "in natura" e não para a industrialização (Cunha, 1987), há necessidade de se conhecer tanto suas propriedades físicas e químicas, como as suas propriedades organolépticas. O presente trabalho estuda a variação estacional das características sensoriais: aspecto, gosto, doçura, acidez, relação doçura/acidez, sucosidade e do critério de nota dos frutos de tangerineira 'Poncã' produzidas sobre diferentes porta-enxertos nas condições edafoclimáticas de Brasília, no Distrito Federal.

\section{MATERIAL E MÉTODOS}

Pomar experimental. Os frutos utilizados para a avaliação de suas características sensoriais foram colhidos em pomar experimental de tangerineira-'Poncã' (Citrus reticulata Blanco), en-

1 (Trabalho 149/2001). Recebido: 00/10/2001. Aceito para publicação: 04/06/2002.

2 Enga Agrâ, M. Sc., Fac. Agronomia e Med. Veterinária/UnB, C. P. 4508, 70910-970 Brasília, DF. Fone: (61) 628 1517 - E-mail: josianazanotelli@hotmail.com

3 Engํㅗ Agro Professor Titular, Fac. Agronomia e Med. Veterinária/UnB. Fone: (61) 3072821 E-mail: atubelis@unb.br 
xertada nos porta-enxertos limoeiros-'Cravo' (LC) e 'Rugoso da África' (LRA); tangerineira- 'Oneco' (TO); citrangeleiro- 'Morton' (CM) e citromeleiro- 'Swingle 4475' (C75), tolerantes ao vírus da tristeza dos citros, existente na Fazenda Água Limpa, de propriedade da Universidade de Brasília, situada no núcleo rural Vargem Bonita, em Brasília, no Distrito Federal (Parente et al., 1993).

Delineamento experimental. A caracterização sensorial dos frutos consistiu em se avaliar as características organolépticas (gosto, doçura, acidez, relação doçura/acidez e sucosidade), a característica visual, o aspecto do gomo e o critério nota. A avaliação das características dos frutos foi feita por um painel sensorial constituído por um grupo de dezoito pessoas habituadas a consumir tangerina-'Poncã', com paladar capaz de distinguir as suas características organolépticas. O delineamento experimental empregado para a análise dos resultados foi o de blocos casualizados. Os tratamentos foram representados pelos portaenxertos das plantas e os blocos pelos degustadores. O método utilizado para a avaliação das características dos frutos foi o de escala hedônica (Morais, 1979).

Preparo das amostras. $O$ início da coleta de frutos para a condução do painel sensorial ocorreu quando algumas plantas apresentavam frutos com mudança de coloração do verde para o amarelo, que é uma das características indicativas do estádio de maturação do fruto, sendo que a primeira coleta ocorreu dia 15 de maio e última dia 03 de julho do ano de 2000. Quatro frutos de cada tratamento foram colhidos no pomar experimental, constituindo uma amostra a ser avaliada pelos degustadores (Santos, 2001).

Condução do painel. No momento da avaliação, dois gomos da amostra, composta por 4 frutos de um tratamento, eram retirados da vasilha com temperatura ambiente, e colocados em um pires branco de porcelana, que era apresentado ao degustador para análise. Cada amostra era acompanhada de sua respectiva ficha de avaliação (Tabela 1.). Avaliaram-se o aspecto visual e as características organolépticas: gosto, doçura, acidez, relação doçura/acidez e avaliação da sucosidade do gomo, levando em consideração as recomendações técnicas (Morais, 1979). O perfil sensorial do gomo foi avaliado pelo critério de nota. Ele consistiu em se atribuir um valor numérico de 0 a 10 ao conjunto de todas as características sensoriais avaliadas. O painel sensorial foi conduzido no Laboratório de Análise de Alimentos da Faculdade de Agronomia e Medicina Veterinária da Universidade de Brasília.

Processamento dos dados. Os resultados das avaliações feitas pelos degustadores foram transformados de escala hedônica para valores numéricos. Esses valores foram usados no cálculo das médias aritméticas das características sensoriais. Os valores originais do critério de nota foram usados na análise de variância do experimento. $\mathrm{O}$ valor das características dos frutos entre as datas de amostragem foi obtido por interpolação linear simples.

Com os valores médios obtidos, foram feitos gráficos para se avaliar o comportamento das características dos frutos. Os valores médios do critério nota foram transformados em valores de escala hedônica, cujas classes foram: de 3,1 a 4,0 para Muito Ruim; de 4,1 a 5,0 para Ruim; de 5,1 a 6,0 para Regular; de 6,1 a 7,0 para Bom; de 7,1 a 8,0 para Muito Bom; de 8,1 a 9,0 para Muitíssimo Bom; e de 9,1 a 10,0 para Excelente.

\section{RESULTADOS E DISCUSSÃO}

Aspecto do gomo. O aspecto do gomo do fruto aumentou em aceitação visual com o decorrer do período de sua maturação. Todos os tratamentos foram enquadrados na classe Agradável, com exceção do tratamento $\mathrm{C} 75$ antes de 23 de maio, e do tratamento LC antes de 06 de junho, que foram enquadrados na classe Regular. Nenhum dos tratamentos foi enquadrado na classe Atrativo, com exceção do tratamento LRA, em 04 de julho.

Gosto de gomo. $\mathrm{O}$ gosto do gomo variou no decorrer do período de amostragem. O gosto piorou para os tratamentos TO e C75, e melhorou para os tratamentos CM, LRA e LC. No início do período de amostragem, os tratamentos TO e C75 foram enquadrados na classe Gostoso e, em 27 de junho, na classe Regular. Os tratamentos CM, LRA e LC foram enquadrados na classe Regular e, no fim do período, na classe Gostoso, com exceção do tratamento LRA, que continuou na classe Regular.

Doçura do gomo. A doçura do gomo variou durante o período de amostragem. Ela aumentou com o passar do tempo para os tratamentos CM, LRA, C75 e LC, e diminuiu para o tratamento TO. O tratamento LC produziu frutos com Pouca Doçura no início do período de amostragem, com doçura Regular no mês de junho e, somente no final de junho, a fruta apresentou-se Doce. A doçura dos frutos correspondentes aos tratamentos CM, C75, TO e LRA superaram a dos frutos referentes ao tratamento LC até 13 de junho, expressa em ordem de grandeza. No caso específico do porta-enxerto limoeiro- 'Cravo', os resultados apresentaram comportamento semelhante aos de porcentagem de sólidos solúveis observados para as condições edafoclimáticas de Lavras e Perdões (Chitarra \& Campos, 1981), no Estado de Minas Gerais, em Botucatu (Cunha, 1987) e Ilha Solteira (Corrêa, 1982), no Estado de São Paulo, e em Vargem Bonita, no Distrito Federal (Oliveira Júnior, 1999). Os resultados para os tratamentos CM, C75 e TO apresentaram comportamento semelhante aos de porcentagem de sólidos solúveis observados em frutos de tangerina-Poncã colhidas em 1998, no mesmo pomar experimental (Oliveira Júnior, 1999). A constatação de diferenças na doçura de frutos obtidos sobre diferentes porta-enxertos discorda dos resultados obtidos por Figueiredo et al. (1973), em Tietê, no Estado de São Paulo, onde os autores verificaram pequena variação no teor de sólidos-solúveis para frutos produzidos sobre diferentes portaenxertos. Contudo, o comportamento da doçura sobre limoeiro'Rugoso da África' foi inverso ao do comportamento da porcentagem de sólidos solúveis observados por Oliveira Júnior (1999), em frutos colhidos em 1998, no mesmo pomar experimental. Essa divergência de resultados deve ter sido causada pela natureza da medida, pela época de colheita dos frutos e por diferenças nas condições climáticas e nutricionais, dentre outros fatores.

Acidez do gomo. A acidez variou durante o período de amostragem, para os tratamentos TO, CM e LRA, e permaneceu relativamente constante para LC e C75. Ela diminuiu com o passar do tempo, para os tratamentos TO e LRA, e aumentou, para o tratamento CM. Os frutos referentes ao tratamento TO foram classificados inicialmente na classe Alta até 23 de maio e na classe Regular a partir de 30 de maio. Os referentes ao tratamento LRA foram classificados na classe Regular em 23 de maio e a partir de 30 de maio na classe Baixa. Os referentes ao tratamento CM foram enquadrados na classe Baixa entre 16 e 23 de maio e na classe Regular a partir de 30 de maio. Os referentes ao tratamento 
C75 permaneceram sempre na classe Baixa, mas muito próximo da separação entre as classes Regular e Baixa. Os referentes ao tratamento LC permaneceram no limite entre as classes Regular e Baixa. De todos os tratamentos, o TO foi o que apresentou frutos com maior acidez durante todo período de amostragem. Os resultados de acidez apresentaram comportamento semelhante ao da acidez expressa em porcentagem de ácido cítrico obtido para tangerineira- 'Poncã' sobre os porta-enxertos citromeleiro'Swingle 4475', limoeiros- 'Cravo' e 'Rugoso da África' e tangerineira-'Oneco', para os frutos colhidos em 1998, no mesmo pomar experimental (Oliveira Júnior, 1999). Contudo, o comportamento foi inverso para os frutos produzidos sobre citrangeleiro- 'Morton'. Os resultados discordam do comportamento do teor de acidez dos frutos de tangerineira 'Poncã' sobre o porta-enxerto limoeiro-'Cravo', obtidos em Lavras e Perdões (Chitarra \& Campos, 1981), no Estado de Minas Gerais, em Botucatu (Cunha, 1987) e Ilha Solteira (Corrêa, 1982), no Estado de São Paulo. Os dois autores verificaram que o teor de ácido cítrico no suco dos frutos foi decrescente durante o período de maturação. Essa aparente divergência de resultados pode ter sido causada pela natureza da medida, pelas diferenças nas condições edafoclimáticas, nutricionais e tratos fitossanitários existentes entre os locais de estudo. Os resultados de acidez obtidos são semelhantes aos obtidos por Figueiredo et al. (1973), em Tietê, no Estado de São Paulo, onde os autores verificaram que os porta-enxertos influenciaram no teor de acidez do fruto.

Relação doçura/acidez. A relação doçura/acidez variou durante o período de amostragem. Ela foi decrescente com o passar do tempo para os tratamentos CM e TO, relativamente estável para o tratamento C75 e crescente para os tratamentos LRA e LC. A relação doçura/acidez referente aos tratamentos CM e C75 foi enquadrada na classe Boa durante todo o período de amostragem. A relação doçura/acidez para o tratamento TO foi enquadrada na classe Boa até 23 de maio e na classe Regular depois de 30 de maio. A relação doçura/acidez para o tratamento LRA permaneceu na classe Regular durante todo período de amostragem. A relação doçura/acidez para o tratamento LC foi enquadrada na classe Fraca até 23 de maio e na classe Regular a partir de 30 de maio. Os resultados mostram que o tratamento LC apresenta uma relação doçura/acidez Fraca antes de 30 de maio e Regular após esta data, não atingindo a categoria Boa até 27 de junho. Estes resultados da relação doçura/acidez apresentaram comportamento semelhante ao da relação de sólidos solúveis/acidez titulável para tangerineira- 'Poncã' sobre o porta-enxerto de limoeiro- 'Cravo', obtida em Lavras e Perdões (Chitarra \& Campos, 1981), no Estado de Minas Gerais, em Botucatu (Cunha, 1987), em Ilha Solteira (Corrêa, 1982), no Estado de São Paulo, e em frutos colhidos em 1998, no mesmo pomar experimental (Oliveira Júnior, 1999). O comportamento da relação doçura/acidez para tangerineira-'Poncã' sobre os porta-enxertos de citrangeleiro-'Morton', citromeleiro- 'Swingle 4475', limoeiro-'Rugoso da África' e tangerineira- 'Oneco' diverge do comportamento relação sólidos solúveis totais/acidez titulável obtidos por Oliveira Júnior (1999), em frutos colhidos em 1998, no mesmo pomar experimental. Essa divergência de comportamento pode ter sido causada pela natureza da medida ou pelas diferenças nas condições climáticas, nutricionais e tratos fitossanitários realizados.

Suculência. A suculência dos frutos variou durante o período de amostragem. Ela aumentou com o passar do tempo, para os tratamentos CM, C75 e LC, decresceu para o tratamento LRA e permaneceu relativamente constante para o tratamento TO. A suculência de todos os tratamentos, durante o período de ensaio, foi enquadrada na classe Regular, com exceção do tratamento CM que, em 27 de junho, foi enquadrado na classe Muito Suco.

O comportamento da suculência obtido diferiu do comportamento do rendimento em suco da tangerina-'Poncã' sobre o porta-enxerto 'limoeiro-Cravo', obtido em Botucatu (Cunha, 1987) e Ilha Solteira (Corrêa, 1982), no Estado de São Paulo. Nesses locais, foi verificado que o rendimento em suco cresceu durante o período de maturação dos frutos, decrescendo no final desse período. Os resultados obtidos foram inversos ao do comportamento da porcentagem de suco observados em frutos colhidos em 1998 no mesmo pomar experimental (Oliveira Júnior, 1999). O comportamento da suculência da tangerina 'Poncã' sobre os porta-enxertos tangerineira 'Oneco' e limoeiro 'Rugoso da África', foi semelhante ao comportamento da porcentagem de suco obtida por Oliveira Júnior (1999), em frutos colhidos em 1998, no mesmo pomar experimental. O comportamento da suculência da tangerina-'Poncã' sobre os porta-enxertos citrangeleiro- 'Morton' e citromeleiro- 'Swingle 4475' foi inverso ao comportamento da porcentagem de suco observada por Oliveira Júnior (1999) em frutos colhidos em 1998, no mesmo pomar experimental. A diferença de comportamento nos resultados obtidos no pomar experimental deve decorrer da natureza da medida da informação, das condições climáticas, época de colheita, das adubações e dos tratos fitossanitários empregados. Os resultados obtidos são semelhantes aos obtidos por Figueiredo et al. (1973), em ensaio de tangerineira 'Poncã' sobre diferentes porta-enxertos, conduzidos em Tietê, no Estado de São Paulo. Os autores verificaram o efeito do porta-enxerto no teor de suco dos frutos.

Nota da fruta A Nota atribuída ao conjunto das características dos frutos variou no período de amostragem, aumentando com o passar do tempo, para os tratamentos LC e CM, diminuindo para os tratamentos $\mathrm{C} 75$ e TO e permanecendo relativamente constante para o tratamento LRA (Figura 1). Resultados semelhantes foram observados em estudo conduzido em Israel, onde foi verificado que o sabor da fruta de tangerineira-'Mineola' variou em cinco locais de duas regiões produtoras (Genizi e Cohen, 1988).

O tratamento TO recebeu pontuação entre 7 e 8 até 13 de junho e entre 6 e 7 a partir desta data, enquanto o tratamento $C 75$ recebeu pontuação entre 7 e 8 até 30 de maio e entre 6 e 7 a partir desta data. Já o tratamento LRA recebeu pontuação ao redor de 7 durante todo o período de amostragem, e o tratamento CM recebeu pontuação entre 7 e 8 durante todo o período de amostragem. $\mathrm{O}$ tratamento $\mathrm{LC}$ recebeu pontuação entre 4 e 5 até 23 de maio, entre 5 e 6 em 30 de maio e 06 de junho e entre 6 e 7 a partir de 13 de junho. O limoeiro- 'Cravo' foi o que apresentou maior variação no valor da nota durante o período de amostragem. Os resultados mostraram que os frutos referentes ao tratamento LC seriam reprovados pelo consumidor até 23 de maio, teriam aceitação regular entre 30 de maio e 06 de junho, e só teriam boa aceitação a partir de 13 de junho. Este fato revela que os portaenxertos tangerineira-'Oneco', citrangeleiro-'Morton', citromeleiro-'Swingle 4475' e limoeiro-'Rugoso da África' antecipam o início da época de colheita dos frutos em relação ao do 
FICHA 1 - Ficha de avaliação das características sensoriais de tangerineira 'Ponkan'.

1- Aspecto do gomo (examine os gomos e classifique)

\begin{tabular}{|l|l|l|l|l|}
\hline Atrativo & agradável & regular & grosseiro & desagradável \\
\hline
\end{tabular}

2- Gosto do gomo (morder o gomo e classificar)

\begin{tabular}{|l|l|l|l|l|}
\hline Muito gostoso & gostoso & regular & insípido & ruim \\
\hline
\end{tabular}

3- Doçura do gomo (morder o gomo e classificar)

\begin{tabular}{|l|l|l|l|l|}
\hline Muito doce & doce & regular & pouco doce & sem doce \\
\hline
\end{tabular}

4- Acidez do gomo (morder o gomo e classificar)

\begin{tabular}{|l|l|l|l|l|}
\hline Muito alta & alta & regular & baixa & sem acidez \\
\hline
\end{tabular}

5- Relação doçura/ acidez (morder o gomo e classificar)

\begin{tabular}{|l|l|l|l|l|}
\hline Muito boa & boa & regular & fraca & ruim \\
\hline
\end{tabular}

6- Sucosidade (morder o gomo e classificar)

\begin{tabular}{|l|l|l|l|}
\hline Muito suco & regular & pouco suco & sem suco \\
\hline
\end{tabular}

7- Nota (avaliação conjunta das propriedades avaliadas, de 1 a 10)

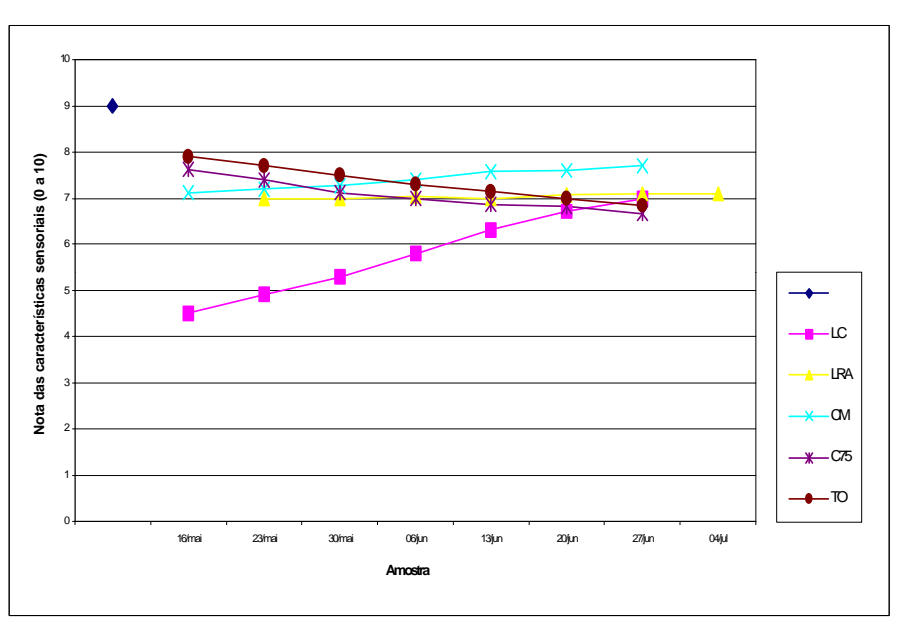

FIGURA 1 - Variação estacional do critério nota do gomo da tangerina-'Poncã' produzida sobre os porta-enxertos limoeiros- 'Cravo' LC e 'Rugoso da África' LRA, citrangeleiro-'Morton' CM, citromeleiro- 'Swingle 4475' C75 e tangerineira- 'Oneco' TO, nas condições edafoclimáticas de Brasília, no Distrito Federal, no ano de 2000. porta-enxerto limoeiro-'Cravo'. Pelo fato de os frutos correspondentes aos tratamentos TO, CM, C75 e LRA terem sido enquadrados na classe Muito Boa, eles poderiam ser colhidos para consumo antes de 23 de maio. Contudo, como os frutos correspondentes ao tratamento LC foram enquadrados na classe Ruim, eles não deveriam ser colhidos para consumo. Os tratamentos TO, CM, LRA e C75 foram enquadrados na classe Muito Boa de 30 de maio a 06 de junho, enquanto LC foi enquadrado na classe Regular. Esses resultados concordam parcialmente com os de Figueiredo et al. (1973), que observaram que o porta-enxerto de trifoliata proporciona frutos de melhor qualidade em relação aos do limoeiro- 'Cravo'. Na data da terceira amostragem, os frutos correspondentes aos tratamentos CM, TO e LRA foram enquadrados na classe Muito Boa, ou Boa e os correspondentes aos tratamentos C75 e LC na classe Boa, indicando a melhor qualidade dos primeiros. Na data da quarta amostragem, os frutos correspondentes aos tratamentos CM e LRA foram enquadrados na classe Muito Boa, e os correspondentes aos tratamentos TO e C75 na classe Boa, e o tratamento LC entre as classes Boa e Muito Boa. Estes resultados evidenciam que a tangerineira'Poncã' não deveria ser cultivada sobre o porta-enxerto de limoeiro-'Cravo', nas condições edafoclimáticas de Brasília, levando em consideração a qualidade sensorial da fruta, pois é muito pequeno o período em que os frutos se apresentam com qualidade Muito Boa. O seu cultivo sobre os outros porta-enxertos empregados neste estudo permitiria colher frutos de qualidade Muito Boa durante um maior período de tempo. 
Em conseqüência desse fato, a substituição do portaenxerto de limoeiro-'Cravo' pelos porta-enxertos tangerineira'Oneco', citrangeleiro-'Morton', citromeleiro-'Swingle 4475' ou limoeiro-'Rugoso da África' permitiria obter frutos de melhor qualidade sensorial durante um maior período do ano. A maior oferta de produto de alta qualidade induziria aumento no consumo e no volume de produção da fruta. Por outro lado, a ampliação do período de armazenamento da fruta no campo reduziria a sazonalidade dos preços, proporcionando maior rentabilidade ao produtor.

\section{CONCLUSÕES}

1. O painel sensorial foi capaz de diferenciar as características sensoriais da tangerina-'Poncã' durante o período de amostragem.

2. As características sensoriais aspecto, gosto, doçura, acidez, relação doçura/acidez e sucosidade do gomo variam durante o período de amostragem.

3. Os porta-enxertos influenciam diferenciadamente no comportamento das características sensoriais dos frutos da tangerineira'Poncã'.

4. O critério Nota do fruto, expresso pelo conjunto das características sensoriais, varia durante o período de amostragem, com comportamento diferenciado conforme o porta-enxerto empregado.

5. Os porta-enxertos que produziram frutos de melhor qualidade pelo critério Nota são o citrangeleiro-'Morton', tangerineira- 'Oneco', limoeiro- 'Rugoso da África', citromeleiro'Swingle 4475' e limoeiro- 'Cravo' em ordem decrescente de grandeza.

\section{REFERÊNCIAS BIBLIOGRÁFICAS}

CCSM - Centro de Citricultura Sylvio Moreira. Dados: A polêmica dos números citrícolas. Informativo Centro de Citricultura, Cordeirópolis, n. 68 , p.3, 2001.

CHITARRA, M. I. K.; CAMPOS, M. A. P. Caracterização de alguns frutos cítricos cultivados em Minas Gerais. IV - Tangerinas (Citrus reticulata Blanco) em fase de maturação. In: CONGRESSO BRASILEIRO DE FRUTICULTURA, 6, Recife, 1981. Anais..., Recife, Sociedade Brasileira de Fruticultura, 1981. V. 2, p. $455-468$.

COELHO, Y. S. Tangerineira para exportação: aspectos técnicos da exportação. Brasília: EMBRAPA_FRUTEX, 1996.72p.

CORRÊA, L. S.; MARTINS, A. B. C.; BIANCO, S. Progressão e maturação dos frutos das tangerineiras 'Cravo' e 'Poncã' ( Citrus reticulata Blanco) e laranjeiras 'Natal' e 'Baia' [Citrus sinensis (L.) Osbeck] cultivadas em Ilha Solteira, SP. In: TROPICAL REGION ASHS CONGRESS, 29., 1981, Campinas, Proceedings... American Society for Horticultural Science, 1982, v. 25, p. 171174.
CUNHA, R. J. P. Competição de tangerineiras 'Cravo', 'Dancy' e 'Ponkan' (Citrus reticulata Blanco) e do tangor 'Murcote' (Citrus sinensis (L.) Osbeck x Citrus reticulata Blanco) em porta-enxerto de limoeiro 'Cravo' (Citrus limonia Osbeck). Botucatu: Faculdade de Ciências Agronômicas, Universidade Estadual Paulista, 1987, 120 p. Tese de Livre-Docência.

DONADIO, L. C.; RODRIGUEZ, O.; TEÓFILO SOBRINHO, J.; IGUE, T. Competição de cultivares de tangerineira-poncã (Citrus reticulata Blanco). In: CONGRESSO BRASILEIRO DE FRUTICULTURA, 2., 1973, Viçosa, Anais..., Viçosa, Sociedade Brasileira de Fruticultura, 1973, v. 1, p. 119-125.

FIGUEIREDO, J. O. de; POMPEU JÚNIOR, J.; RODRIGUEZ, O.; VEIGA, A. de A.; ABRAMIDES, E. Competição de dez portaenxertos para a tangerineira-poncã (Citrus reticulata Blanco). In: CONGRESSO BRASILEIRO DE FRUTICULTURA, 2., 1973, Viçosa, Anais..., Viçosa: Sociedade Brasileira de Fruticultura, 1973, v.1,p.127-147.

GENIZI, A.; COHEN, E.; The chemical composition, and sensory flavour quality of 'Mineola' tangerines. II. Relationship between composition and sensory properties. Journal of Horticultural Science, v. 63, n. 1, p. 179-182, 1988.

HODGSON, R. W. Horticultural varieties of citrus. In: REUTHER, W.; WEBBER, H. J.; BATCHELOR, L. D., The Citrus Industry. Berkelly: University of California, 1967, v.1, cap. 4. p. 431-591. MORAIS, M. A. C. Métodos para avaliação sensorial de alimentos, Campinas, Faculdade de Engenharia de Alimentos e Agrícola - UNICAMP, 1979, 87p. $2^{\text {a }}$ ed.

NEVES, C. S. V.J.; DECHEN, A. R.; FELLER, C.; GONZÁLEZ, M. G. N. Influência de sistemas de manejo de solo em pomar de tangerineira 'Poncã' sobre limoeiro ‘Cravo' em Latossolo Roxo. Revista Brasileira de Fruticultura, Jaboticabal, v. 20, n.3, p. 367-374, 1998.

OLIVEIRA JÚNIOR, M. E. Produtividade e características físico-química dos frutos de tangerineira 'Ponkan' (Citrus reticulata Blanco)sobre 14 porta-enxertos na Vargem Bonita, DF. Brasília: Faculdade de Agronomia e Medicina Veterinária, Universidade de Brasília, 1999, 89p. Dissertação de Mestrado.

PARENTE, T. V.; WECHESLER, F. S.; BORGO, L. A.; REZENDE, L. P. Comportamento da tangerineira 'Ponkan'(Citrus reticulata Blanco) sobre 14 porta-enxertos do Distrito Federal. In: Congresso Brasileiro de Fruticultura, Cruz das Almas, v. 15, n. 1, p.35-41, 1993.

SANTOS, J. Z. dos Variação estacional das característica sensoriais de frutos de tangerineira 'Ponkan' (Citrus reticulata Blanco), produzidos sobre cinco porta-enxertos, nas condições edafoclimáticas de Brasília. Brasília: Faculdade de Agronomia e Medicina Veterinária, Universidade de Brasília, 2001, 72 p. Dissertação de Mestrado. 